\title{
Design considerations and strengthening mechanisms in developing Co-Re-based alloys for applications at $+100^{\circ} \mathrm{C}$ above $\mathrm{Ni}$-superalloys
}

\author{
Debashis Mukherji $^{\mathrm{a}}$ and Joachim Rösler ${ }^{\mathrm{b}}$
}

\author{
Technische Universität Braunschweig, IfW, Langer kamp 8, 38106 Braunschweig, Germany \\ ad.mukherji@tu-bs.de, bj.roesler@tu-bs.de
}

Key words: Co-Re alloys, superalloy, alloy development

\begin{abstract}
Although Ni-base superalloys meet the gas turbine needs of today, they are used very close to their melting range. Demands for applications at higher temperatures are presently met partly through component cooling and application of thermal barrier coatings. However, this approach can not be sustained indefinitely unless the base metal melting temperature is also significantly increased. Rhenium addition can substantially increase the melting point in Co-base alloys and thereby provide a unique opportunity in the development of new alloys for very high temperatures - e.g. for applications at $+100^{\circ} \mathrm{C}$ metal temperature above present day single crystal Ni-base superalloys. The design considerations behind the Co-Re alloy development are presented in this paper. Selected results from the alloy development studies are also presented.
\end{abstract}

\section{Introduction}

Development of high temperature materials is mainly driven by gas turbine needs. Today, Ni-base superalloys are the dominant material class in the hot section of turbines. Improving the temperature capability of superalloys, which are already used very close to their melting range $\left(1300^{\circ}-1400^{\circ} \mathrm{C}\right)$ is limited by the possibility to raise further their melting point. Many efforts are being made worldwide for developing new alloy systems to supplement Ni-base superalloys in future [1]. A novel concept of using Co-Re-base alloys was introduced by us to meet this demand [2]. The goal is to develop Co-Re alloys for applications at $+100^{\circ} \mathrm{C}$ (metal temperature) above present day single crystal Ni-base superalloys.

The refractory metal Re has the third highest melting point $\left(3182^{\circ} \mathrm{C}\right)$ amongst the elements in the periodic table, which is more than double the melting point of Co $\left(1495^{\circ} \mathrm{C}\right)$. Moreover, it dissolves readily in Co and a complete miscibility exists in the Co-Re system ( Re in Ni has only a limited solubility). Due to the unlimited solubility of $\mathrm{Re}$ in $\mathrm{Co}$, it is possible to continuously increase the melting temperature of Co alloys with the addition of Re. This opens up a unique possibility to steadily elevate the melting range in the Co-Re system, changing the character of the material from that of a contemporary Co-based alloy to that of a high melting point material. Further, the "tuneability" in the Co-Re system gives a good chance to find a proper balance between the need for toughness and ductility on the one hand and strength at temperatures beyond the capability of Ni-base superalloys on the other hand.

It is clear that for technical alloys, further alloying additions are needed to impart sufficient strength and oxidation resistance. Judicious alloying gives a good possibility to tune the microstructure in Co-Re-base alloys and explore new concepts in strengthening. Keeping oxidation resistance in mind, in addition to the high temperature strength need, $\mathrm{Cr}$ and a small amount of $\mathrm{Si}$ was explored with good success $[3,4]$. In this contribution we briefly present the general development strategy and design considerations adapted for the Co-Re-Cr base alloy development. Since the microstructural aspects of the strengthening phases and the oxidation behaviour of Co-Re$\mathrm{Cr}$ base alloys have been published earlier [3-6], here we will present some highlights from the recent results. Particularly, we will present (i) tensile results from the alloys with B addition and (ii) the effect of Ni addition on the sigma phase morphology and the ductility of the Co-Re alloys. 


\section{Alloy Development Strategy}

Co-based alloys are not new and are presently used in gas turbines for static parts up to $1000^{\circ} \mathrm{C}$. In the conventional cast Co-base alloys, the matrix phase has a face centred cubic (fcc) $\gamma$ structure. There is even a new development trend in Co-Al-W alloys [7] to produce a $\gamma / \gamma$ ' structure $\left(\mathrm{fcc} / \mathrm{L1}_{2}\right)$ similar to that in $\mathrm{Ni}$ superalloys to improve strength. However, this does not promise application temperatures beyond Ni-superalloys. We believe that to develop alloys for very high temperature application, one needs an alloy system with relatively high melting point. The Co-Re system meets this criterion. In fact, the Co-Re system offers the possibility to suitably adjust the melting range by the amount of $\mathrm{Re}$ addition. About 17 atomic percent $\mathrm{Re}$ addition to $\mathrm{Co}$ can raise the liquidus temperature from $1495^{\circ} \mathrm{C}$ in pure Co to $\sim 1700^{\circ} \mathrm{C}$ in the Co-17Re binary alloy (Fig. 1). In the experimental Co-Re alloys, Re

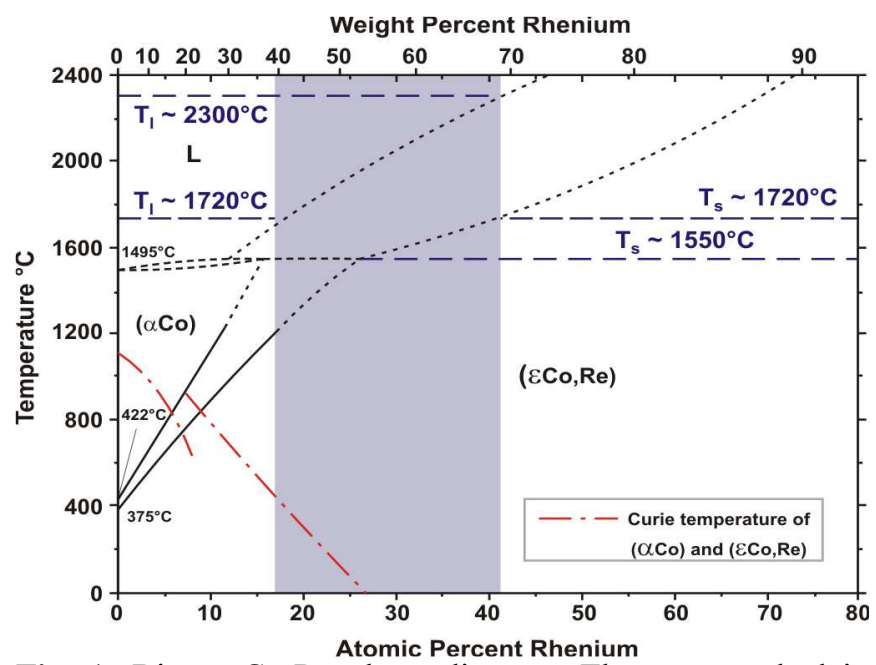

Fig. 1: Binary Co-Re phase diagram. The area marked in blue show the composition range of interest for the high temperature Co-Re alloys.

addition stabilizes the hexagonal close packed (hcp) $\varepsilon$ Co phase as the matrix, which is the thermodynamically stable low temperature allotromorph of Co. This distinguishes Co-Re base alloys from the conventional Co alloys, where the matrix is fcc (the high temperature Co phase) and it required a new strategy in the Co-Re alloy development.

In actual, the Co-Re system has been seldom investigated in the past and only a small number of articles exist. They mainly relate to structural investigations and phase diagrams [e.g. 8]. The first step in our alloy development, therefore, was to explore different strengthening possibilities in the Co-Re system. A more fundamental approach of using simple model alloy compositions was followed in this program. Strengthening mechanisms like precipitation hardening by carbide precipitates $\left(\mathrm{M}_{23} \mathrm{C}_{6}\right.$ and $\mathrm{MC}$ types), solid-solution hardening by large atoms (e.g. Re) or composite strengthening with second phase particles ( $\sigma$ phase) were explored. Initial studies with the cast polycrystalline Co-Re alloys showed that grain boundary embrittlement is a critical issue in this system, which limit both the strength and the ductility of the alloys at room and high temperatures. Taking clue from polycrystalline Ni superalloy development of the past, addition of B (and $\mathrm{Zr}$ ) was considered in experimental Co-Re alloys.

It is mentioned above that along with high temperature strength, oxidation resistance is an important aspect in high temperature alloy development. The Co-Re alloys were never investigated for oxidation behaviour before this programme. Therefore, in order to understand the fundamental aspects of oxidation, i.e. the role different alloying element addition plays on oxidation behaviour of the CoRe-alloys, there was a need to isolate the effect of each alloying element on i) strength and ii) oxidation and study them separately. One set of model alloy compositions was designed for studying the strengthening mechanisms and another set of compositions for the oxidation behaviour. Even for strengthening, the different mechanisms were explored separately with tailored alloy compositions. The knowledge gained from these studies provides the basis for the design and development of a technical alloy. $\mathrm{Cr}$ which promotes the formation of a protective $\mathrm{Cr}_{2} \mathrm{O}_{3}$ oxide layer in conventional iron, nickel and cobalt alloys was a logical choice as an alloying addition for intermediate temperature oxidation resistance. It was quite clear however, that chromium alone can not suffice for oxidation protection at higher temperatures and therefore a small amount of $\mathrm{Si}$ addition in conjunction with $\mathrm{Cr}$ was explored. This provided good oxidation resistance to $1100^{\circ} \mathrm{C}$ [4]. For further improvement in oxidation behaviour addition of $\mathrm{Al}$ will be considered in the future. 
However, addition of $\mathrm{Cr}$ to Co-Re alloys stabilizes a significant amount of the Cr-Re-rich $\left(\mathrm{Cr}_{2} \mathrm{Re}_{3}\right.$ type) $\sigma$ phase (Sp. Gp. no. 136). The topologically closed packed (tcp) $\sigma$ phase has a very high strength, but unfortunately, it is also a very brittle phase and therefore is generally undesirable in $\mathrm{Ni}$ and $\mathrm{Fe}$ base alloys. A novel development strategy is adapted for the Co-Re alloy development in which a new concept of composite strengthening using the $\sigma$ phase is explored; thereby the very strong $\sigma$ phase is used for high temperature strengthening of the alloy. The $\sigma$ phase is very stable at high temperatures up to $1300^{\circ} \mathrm{C}$. Thereby, two main paths for alloy strengthening are followed in our development strategy - i) precipitate strengthening by carbides, particularly MC type and ii) composite strengthening using $\sigma$ phase. In both cases, additional strengthening through solid solution effects of $\mathrm{Re}$ and strengthening of grain boundaries by $\mathrm{B}$ and $\mathrm{Zr}$ is combined. Extensive thermodynamic calculations (to calculate multi-component phase diagrams using ThermoCalc software) guided the choice of alloy compositions in this development work.

\section{Experimental}

Material and heat treatment. A number of model alloys: divided into two groups - i) alloys for studying strengthening behaviour and ii) alloys for studying oxidation behaviour were prepared by vacuum arc melting either as small buttons $(100 \mathrm{~g})$ or as cast bars $\left(12 \times 12 \times 70 \mathrm{~mm}^{3}\right)$. The alloy compositions in two groups are listed in table 1. Alloys were heat treated at different ageing temperatures to control the size and dispersion of second phase (carbides or $\sigma$ ). The choice of heat treatment temperatures were based on the thermodynamic calculations of phase stability as a function of temperature and composition. Model alloys for strength (table 1) were solution treated in the temperature range $1400^{\circ}-1450^{\circ} \mathrm{C}$ and aged between $1000^{\circ}-1225^{\circ} \mathrm{C}$.

Table. 1: Model alloy compositions (atomic \%) of Co-Re-Cr based system

\begin{tabular}{|c|c|}
\hline Alloy Composition & Purpose \\
\hline \multicolumn{2}{|l|}{ Model alloys for Strength: } \\
\hline 1. $\mathrm{Co}-17 \mathrm{Re}-23 \mathrm{Cr}$ & Base alloy composition for reference \\
\hline 2. Co-17Re-23Cr-2.6C & Alloy strengthening by $\mathrm{M}_{23} \mathrm{C}_{6}$ type $\mathrm{Cr}$-carbide \\
\hline 3. Co-17Re-23Cr-1.2Ta-2.6C & Alloy strengthening by $\mathrm{M}_{23} \mathrm{C}_{6}$ type $\mathrm{Cr}$-carbide $+\mathrm{MC}$ type Ta-carbide \\
\hline 4. $\mathrm{Co}-30 \mathrm{Re}-23 \mathrm{Cr}$ & Alloy with higher Re content (high melting point) \\
\hline 5. $\mathrm{Co}-17 \mathrm{Re}-23 \mathrm{Cr}-15 \mathrm{Ni}$ & Composite strengthening by $\sigma$ phase particles (Ni addition) \\
\hline 6. $\mathrm{Co}-17 \mathrm{Re}-23 \mathrm{Cr}-25 \mathrm{Ni}$ & Composite strengthening by $\sigma$ phase particles (higher Ni) \\
\hline $\begin{array}{l}\text { 7. Co-17Re-23Cr-2.6C + } 200- \\
1000 \text { ppm B and } 500-2000 \\
\text { ppm Zr }\end{array}$ & Alloys with B and $\mathrm{Zr}$ additions for grain boundary strengthening \\
\hline \multicolumn{2}{|l|}{ Model alloys for Oxidation: } \\
\hline 1. $\mathrm{Co}-17 \mathrm{Re}$ & Binary Co-Re \\
\hline 2. $\mathrm{Co}-23 \mathrm{Cr}$ & Binary Co-Cr \\
\hline 3. $\mathrm{Co}-17 \mathrm{Re}-23 \mathrm{Cr}$ & Ternary Co-Re-Cr (same as reference alloy) \\
\hline 4. $\mathrm{Co}-17 \mathrm{Re}-30 \mathrm{Cr}$ & Ternary Co-Re-Cr (with higher $\mathrm{Cr}$ ) \\
\hline 5. $\mathrm{Co}-23 \mathrm{Cr}-2.6 \mathrm{C}$ & Ternary Co-Cr-C \\
\hline 6. $\mathrm{Co}-17 \mathrm{Re}-23 \mathrm{Cr}-2.6 \mathrm{C}$ & Alloy strengthening by $\mathrm{M}_{23} \mathrm{C}_{6}$ type $\mathrm{Cr}$-carbide \\
\hline 7. $\mathrm{Co}-17 \mathrm{Re}-30 \mathrm{Cr}-2.6 \mathrm{C}$ & Alloy strengthening by $\mathrm{M}_{23} \mathrm{C}_{6}$ type $\mathrm{Cr}$-carbide (higher $\mathrm{Cr}$ ) \\
\hline 8. $\mathrm{Co}-17 \mathrm{Re}-23 \mathrm{Cr}-1 \mathrm{Si}$ & Alloy with $\mathrm{Cr}$ and $\mathrm{Si}$ \\
\hline 9. $\mathrm{Co}-17 \mathrm{Re}-23 \mathrm{Cr}-3 \mathrm{Si}$ & Alloy with $\mathrm{Cr}$ and higher $\mathrm{Si}$ \\
\hline 10. Co-17Re-30Cr-2Si & Alloy with higher $\mathrm{Cr}$ and $\mathrm{Si}$ \\
\hline
\end{tabular}

In this paper mainly the results from Co-17Re-23Cr, Co-17Re-23Cr-15Ni and Co-17Re-23Cr + 500 ppm B, designated CoRe-ref., CoRe-5 and CoRe-8 respectively, are presented. 
Characterization methods. Structural and microstructural investigations were carried out using conventional methods. While optical and electron microscopy were used for microstructural characterisation, X-ray, synchrotron and neutron diffraction were used for structural characterization. A Leo 1550 FEG scanning electron microscope (SEM) equipped with EDS, WDS

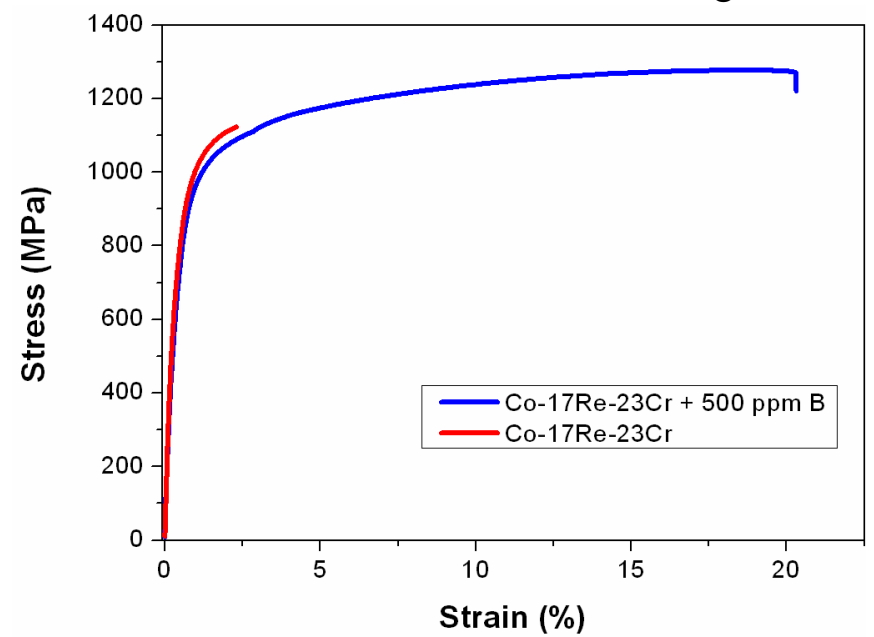

Fig. 2: Room temperature tensile data from CoRe-ref. and CoRe- 8 alloys show improved ductility due to B addition. and EBSD detectors, a Philips CM 12 TEM operating at $120 \mathrm{KV}$ and a GE 3003 PTS XRD are available at IfW TUBruanschweig. Room temperature tensile tests were done in a Zwick $200 \mathrm{KN}$ universal testing machine.

\section{Results and discussion}

Effect of Boron addition. Although the exact melting temperature of the Co-Re alloys is not yet determined, the alloys have high melting points, above $1550^{\circ} \mathrm{C}$. This is at least $150^{\circ} \mathrm{C}$ above present day single crystal Ni-base superalloys. In DSC measurement on the reference alloy (Co17Re-23Cr) up to $1550^{\circ} \mathrm{C}$ (maximum possible temperature in the available instrument) no incipient melting was observed.

Room temperature tensile data from alloys CoRe-ref. and CoRe- 8 are compared in Fig. 2. It shows that the reference alloy is rather brittle at room temperature (RT) and fractures intergranularly (Fig. 3a). In contrast the CoRe-8 alloy is ductile and fails at $\approx 20 \%$ strain. The fracture surface from the CoRe-8 sample is shown in Fig. 3b. An addition of a small amount of B (in ppm level) has a dramatic effect and it is found that B mitigates environmental embrittleness in Co-Re alloys. Room and high temperature bend tests further showed that $\mathrm{B}$ addition as low as 200 ppm can increase strength and ductility in these

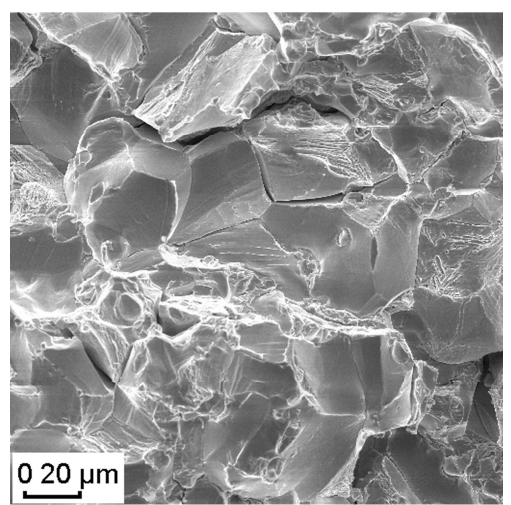

Fig. 3: Fracture surfaces after room temperature tensile tests of alloys CoRe-ref. and CoRe-8 show the beneficial effect of B addition. alloys.

$\mathrm{Ni}$ addition and $\sigma$ phase morphology. The thermodynamic calculation showed that the ternary Co-Re-Ni alloys are solid solutions of Co, like the binary Co-Re alloys and no intermetallics or tcp phases occur. However, when a quaternary addition of $\mathrm{Cr}$ is made, the tetragonal $(\mathrm{Co}, \mathrm{Cr})_{2} \mathrm{Re}_{3} \sigma$ phase becomes thermodynamically stable. The $\mathrm{Cr}$ and Re rich $\sigma$ phase is also stable at RT in ternary Co-Re-Cr alloys, i.e. the CoRe-ref. (Fig. 4a). The SEM image in Fig.4a shows a hardness impression and it can be seen that the $\sigma$ phase particles are brittle and develop cracks due to deformation caused by the hardness indentation. However, it is interesting to note that the alloy as such is not inherently brittle. There is large plastic deformation in the matrix, indicated by slip band formation near the hardness indentation. Moreover, as $\sigma$ particles are isolated, they do not provide an easy crack path. 
In the CoRe-ref. alloy the $\sigma$ phase is distributed as large (5 to $10 \mu \mathrm{m})$ particles at the grain

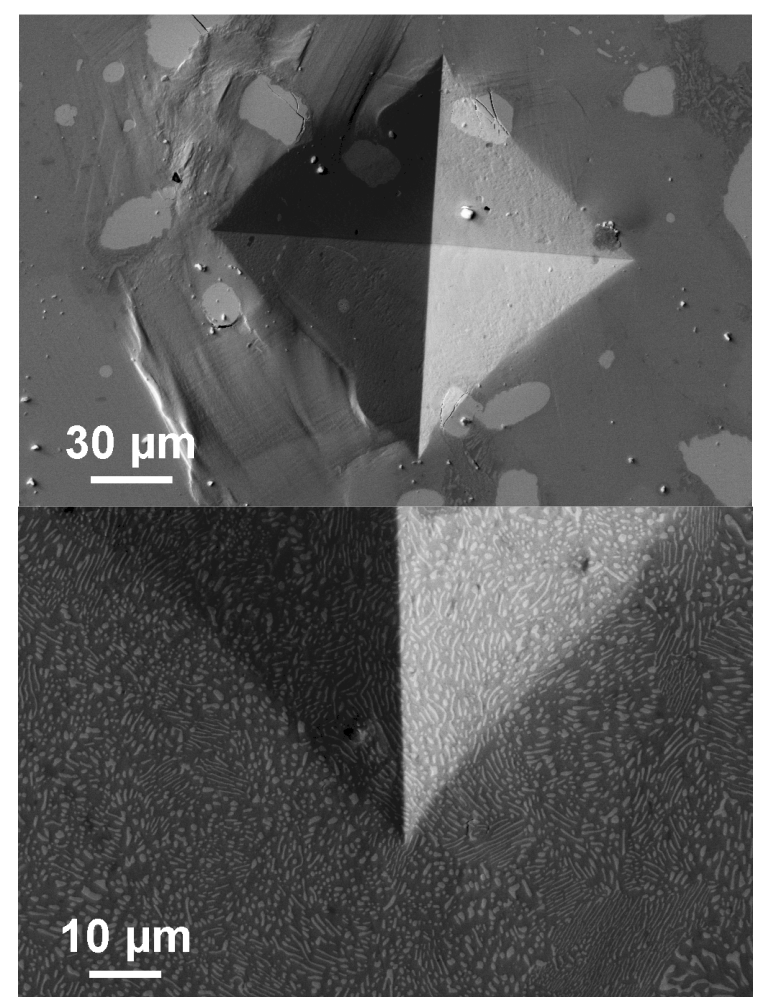

Fig. 4: SEM images of CoRe-ref. and CoRe-5 alloys after heat treatment showing $\sigma$ phase distribution. The images also show hardness indentation mark and the deformation around the indentation. boundaries and within the grains. Addition of $\mathrm{Ni}$ to the Co-17Re-23Cr composition has a dramatic effect on the $\sigma$ phase morphology. Fig. $4 \mathrm{~b}$ shows an SEM image of the CoRe-5 alloy aged at $1225^{\circ} \mathrm{C}$ for 3 hours. In this heat treated condition the $\sigma$ phase particles are very finely dispersed $(<100 \mathrm{~nm}$ in size) in the Co matrix. More interestingly, the $\sigma$ phase present in such a fine dispersion, is no more brittle. This is clearly seen in Fig. 4b which shows that no cracks form in the $\sigma$ particles around the hardness indentation. Microhardness measurements have shown that the $(\mathrm{Co}, \mathrm{Re})_{2} \mathrm{Cr}_{3} \sigma$ phase is very strong having a typical hardness value of $1540 \mathrm{HV}$. This is an ideal microstructure for high temperature creep resistance and therefore provides the possibility for a novel concept of developing a two phase composite alloy hardened by the topologically closed packed $\sigma$ phase. Long time exposures (up to $1000 \mathrm{~h}$ ) at high temperatures $\left(1000^{\circ}-1200^{\circ} \mathrm{C}\right)$ showed that the $\sigma$ phase morphology in the CoRe-5 alloy is very stable and only a slight coarsening of the $\sigma$ phase occurs (Fig. 5).

\section{Summary and outlook}

The Co-Re system has never been explored so far and basic understanding was needed before developing a high temperature technical alloy for gas turbine application. A beginning has been made in Co-Re alloy development and it shows great potential. The recent investigations have identified potential strengthening mechanisms and showed us how the oxidation and the environment embrittlement problems can be addressed. Stage is now set for starting the development of a first generation technical alloy.

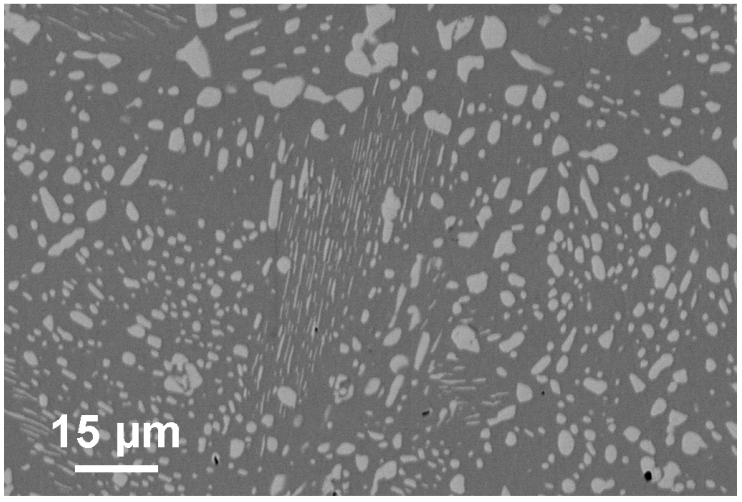

Fig. 5: $\sigma$ phase morphology in heat treated CoRe-5 alloy sample after $300 \mathrm{~h}$ exposure at $1200^{\circ} \mathrm{C}$.

\section{Acknowledgements}

Financial support by the Deutsche Forschungsgemeinschaft in the frame of the research project "Beyond Nickelbase Superalloys" is gratefully acknowledged. 


\section{References}

[1] M. Heilmaier, M. Krüger, H. Saage, J. Rösler, D. Mukherji, U. Glatzel, R. Völkl, R. Hüttner, G. Eggeler, Ch. Somsen, T. Depka, H.-J. Christ, B. Gorr, and S. Burk, JOM Vol. 61 (2009), p. 61

[2] J. Rösler, D. Mukherji and T. Baranski, Adv. Eng. Mater. Vol. 9 (2007) p. 876

[3] M. Klauke, D. Mukherji, B. Gorr, H. -J Christ and J. Rösler, Int. J. Mat. Res. Vol. 100 (2009) p. 104

[4] B. Gorr, V. Trindade, S. Burk, H.-J. Christ, M. Klauke, D. Mukherji and J. Rösler, Oxid. Metal vol. 71 (2009) 157

[5] T. Depka, Ch. Somsen, G. Eggeler, D. Mukherji, J. Rösler, M. Krüger, H. Saage and M. Heilmaier, Mat. Sci. Eng. Vol. A 510-511 (2009) p. 337

[6] D. Mukherji, M. Klauke, P. Strunz, I. Zizak, G. Schumacher, A. Wiedenmann and J. Rösler, Int. J. Mat. Res. Vol. 101 (2010) p. 340

[7] J. Sato, T. Omori, K. Oikawa, I. Ohnuma, R. Kainuma, K. Ishida, Science Vol. 312 (2006) p. 90

[8] E. M. Sokolovskaya, M.L. Tuganbaev, G. I. Stepanova, E. F. Kazakova and I. G. Sokolova, J. Less-Common Metals Vol. 124 (1986) p. L5 